\title{
The Design of an Automated Syringe-Type Smoking Machine*
}

\author{
by R. M. Wiley and J. A. Ferri \\ Philip Morris Research Center, Richmond, Virginia, USA
}

INTRODUCTION

In 1958 O'Keeffe and Lieser (1) published their work on the development of an eight-port smoking machine. The capacity of this machine was later increased to twenty ports, but this change greatly magnified the inherent problem of accurately cutting the cigaret coals at the desired butt length. To eliminate this problem, a means of automatically and accurately controlling the butt length was needed. A device was developed for this purpose, and this report describes the operation of a syringe-type smoking machine that has been automated and equipped with a butt length controller.

The smoking machine herein described is a modified twenty-port constant volume machine of the type developed by O'Keeffe and Lieser (I). This new machine is fully automated electrically, and incorporates a remote control unit that allows the operator to manually operate the individual ports or the entire machine. A twenty-port electric lighter ignites all cigarets simultaneously. (This lighter and an accurate cigaret butt length marking device is described later in this paper.) Microswitches and thread-holding posts are mounted on a support bar through which the cigarets are passed into the Cambridge filter holders. The support bar also holds the cigaret firmly against the thread at all times. The application of this "string-trigger" mechanism permits an accurate and instant means of cut-off of the puffing of the cigaret at the designated butt length $(30 \mathrm{~mm})$. When the thread is burned through at the $30 \mathrm{~mm}$ butt length, it triggers an electric impulse which initiates a series of chain reactions that effectively terminate the puffing action of the smoking machine. Impulse counters, wired into the control system, automatically record the number of puffs per cigaret.

\section{DESIGN AND CONSTRUCTION}

The basic concept of this automated smoking machine is illustrated in block diagram form in Figure I.

The smoking machine is a 20-port constant volume syringe-type set to take a $35 \mathrm{cc} \pm 0.5$ puff of 2.0 \pm o.2-second duration at one-minute intervals. The bottom horizontal syringe support shafts have been equipped with individually adjustable eccentric cams at each syringe to permit accurate volume adjustment on each port. A three-way solenoid valve is mounted on each syringe and is part of the smoking train. The solenoid valves not only stop the puffing action, but also serve as inlet and exhaust valves for the syringe. This replaces the ball check valves used by O'Keeffe and Lieser and eliminates a potential leak problem as well as chatter in the puff profile.

*Reprinted with permission from "Tobacco"-New York, Vol. 165, No. 16, pp. 30-33 (Tobacco Science Vol. XI, pp. 140-143), October 20, 1967. Presented at the 20th Tobacco Chemists' Research Conference held in Winston-Salem, North Carolina, November 1966. 
The variable speed control on the drive unit of the smoking machine permits accurate adjustment of the $2.0 \pm 0.2$-second puff duration (see Figure $1-D$ ). Hence a $35 \pm 0.5$-cc volume in the syringes and a 2-second speed setting assures reproducibility of puff volume and duration regardless of the resistance (pressure drop) of the cigaret over a range of 0 to 8 inches of water. Volume calibration is normally made with an "in-line" resistance of 4.5 inches to compensate for the average resistance of cigarets. The gear driven motor is D.C. powered and the voltage is regulated to prevent speed variation due to load changes.

A half-inch plexiglass bar was bored with holes spaced to coincide with the Cambridge holders and forms the support bar. The cigaret, for a given port, passes from the Cambridge holder through the hole in the support bar and is held firmly in a horizontal position. The hole size is such that the cigaret is held firmly yet not so tight as to crimp the cigaret and alter its pressure drop.

On the front of the support bar, and spaced evenly between the holes, are mounted hollow brass posts. Secured into each post is a small coiled spring which entraps and positions the "stringtrigger" thread. Microswitches are mounted on the back of the support bar and directly opposite the posts (see Figure 2). The support bar is mounted in front of the Cambridge holders and is secured in place at each end of the smoking cabinet.

The wires from the microswitches and solenoid valves lead to the electrical distribution power supply which will be described later in the section on materials. A remote control unit equipped with push buttons is connected to the power supply to permit manual control of the solenoid valves if a microswitch should fail (see Figure I-A, B, C \& D). The entire machine can be operated manually if desired.

FIGURE 1

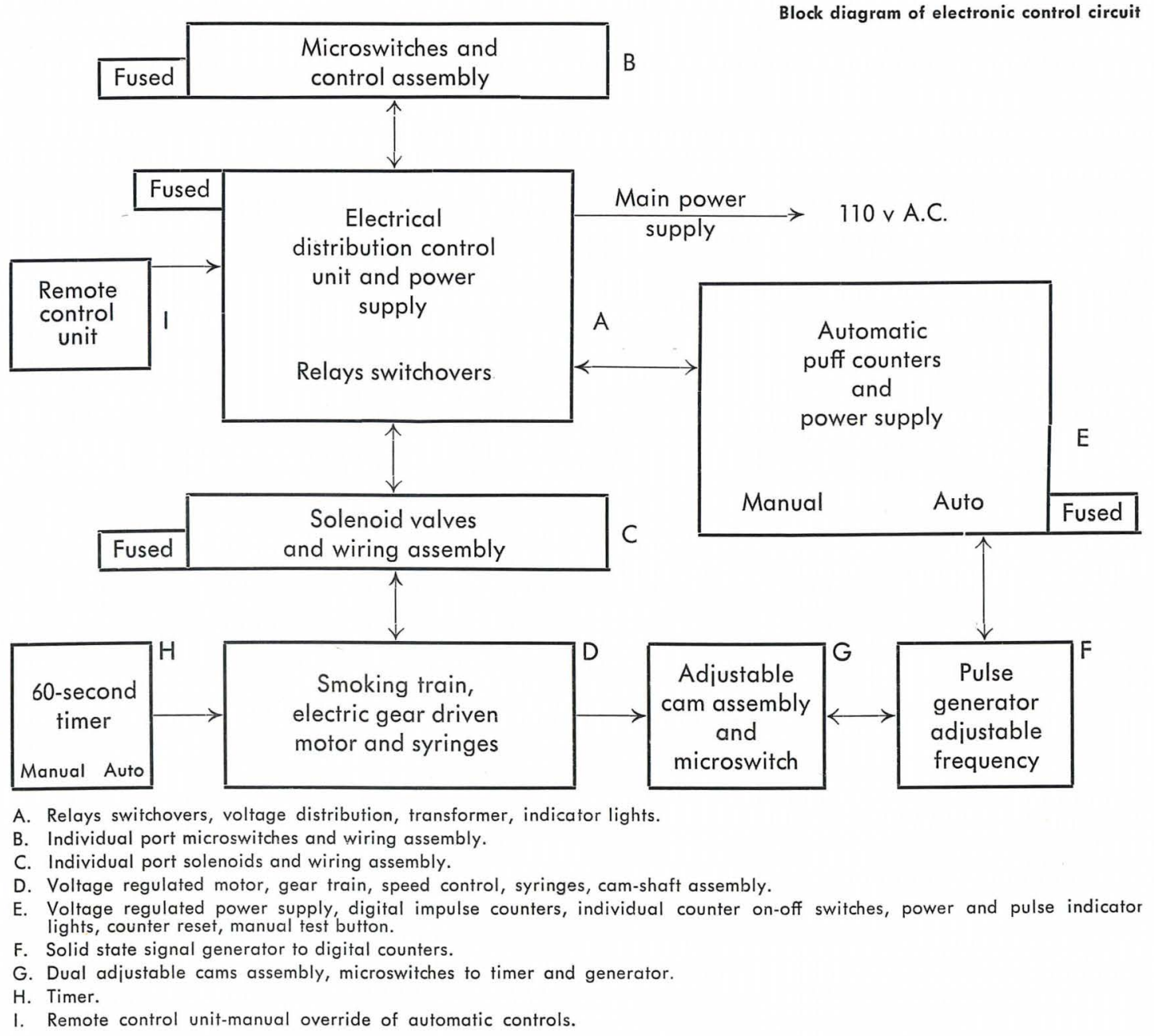




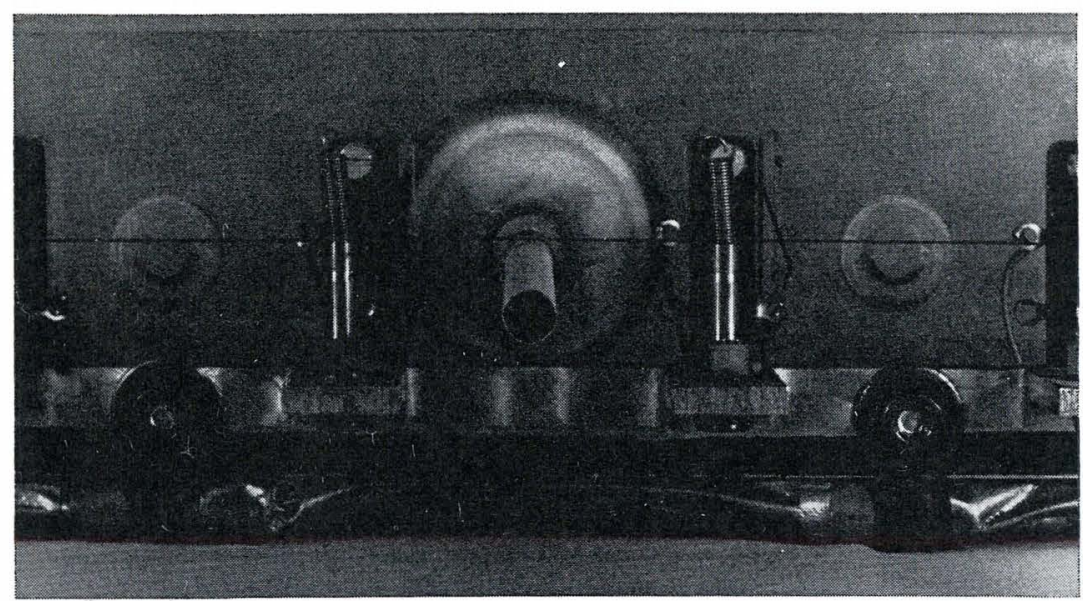

Twenty impulse counters, electrically connected to the power supply unit, are used to record puff counts automatically. These digital read-out counters are mounted in an aluminum mini-box equipped with an on-off power switch, power indicator light and safety fuse. Each counter is equipped with push button reset and an on-off switch (see Figure 1-E).

Electrically attached to the counter unit is a separately housed impulse signal generator. This generator is coupled electronically to a microswitch on a 2 -second adjustable cam which is mounted directly on the syringe shaft (see Figure I-F \& G). The signal generator pulses at 5 pulses per second ( $10 / 2$ seconds) and activates the counters. A 4-second cam and microswitch is also mounted directly on the syringe shaft. When this switch is energized, either manually or by a 6o-second electric timer (see Figure $1-\mathrm{H}$ ), the smoking machine shafts make one complete revolution.

During the 4-second machine rotation, the 2-second cam and microswitch energizes and de-energizes the counters at exactly the moment the 2-second puff begins and stops. Thus, one 2-second puff is recorded on the counters as ten units. The last puff is consequently measured as a fraction of a puff, depending on when the string cut-off stops the puff. A counter that has energized for $8^{1 / 2}$ puffs will show a count of 85 .

Individual counter on-off switches permit the operator to de-energize any single counter if a cigaret fails to light, reset to zero and energize the counter on the next puff as the given cigaret is hand lit. An alternative would be to de-energize the counter (showing Io counts) until after the hand lighting puff and then energize it for the succeeding puffs.

Material

Three-way solenoid valves (Skinner V530A1075) are inserted in the smoke train of a twentyport constant volume machine. Small microswitches (Robertshaw CWLD-1) that electrically operate the solenoid valves are mounted on the back of a plexiglass support bar which is bored at proper intervals to permit the cigarets to pass through the bar. The bar is placed immediately in front of the Cambridge filter holders.

Wires from the solenoid valves and the microswitches lead to a common electrical distribution power supply. The power supply source is comprised of low voltage operating relays (Potter Brumfield KRPIIAN) powered by a step-down voltage transformer rated at $6.3 \mathrm{v}$ at 6 amps A.C. (Stancor P6456). Also included is another step-down transformer rated at $6.3 \mathrm{v}$ at 10 amps A.C. (Stancor P6308) and yielding D.C. voltage. This is for the purpose of operating digital counters and associated components.

The solenoid valves are operated from the same power supply and are energized by action of the relays through the microswitches. Simultaneously, impulse digital counters (Presin Q23RA) recording puff counts, via a pulse signal generator (Whiddett $580 \mathrm{D}$ ), are de-energized by the action of the relays.

The 20-port electric cigaret lighter simultaneously lights all cigarets. A 75-watt cigar lighter element (Eagle 445) with a screw base is used for ignition. 
Preparatory to smoking, the cigarets are inserted through the holes in the support bar and into the Cambridge holder dental dam (about $5 \mathrm{~mm}$ ) until the mark indicating the butt length rests in line with the thread posts (see Figure 3). The operator stretches a "heavy duty" mercerized thread across the front of the support bar and secures the thread on each post by raising the spring and trapping the thread in the coils as the spring is lowered. As the thread is lowered, it contacts the microswitch actuator arms and depresses them. The thread rests on top of the cigaret which the operator adjusts until the butt length mark is obscured by the thread. The cigarets are lit with the 20-port electric lighter which is described in detail later.

FIGURE 3

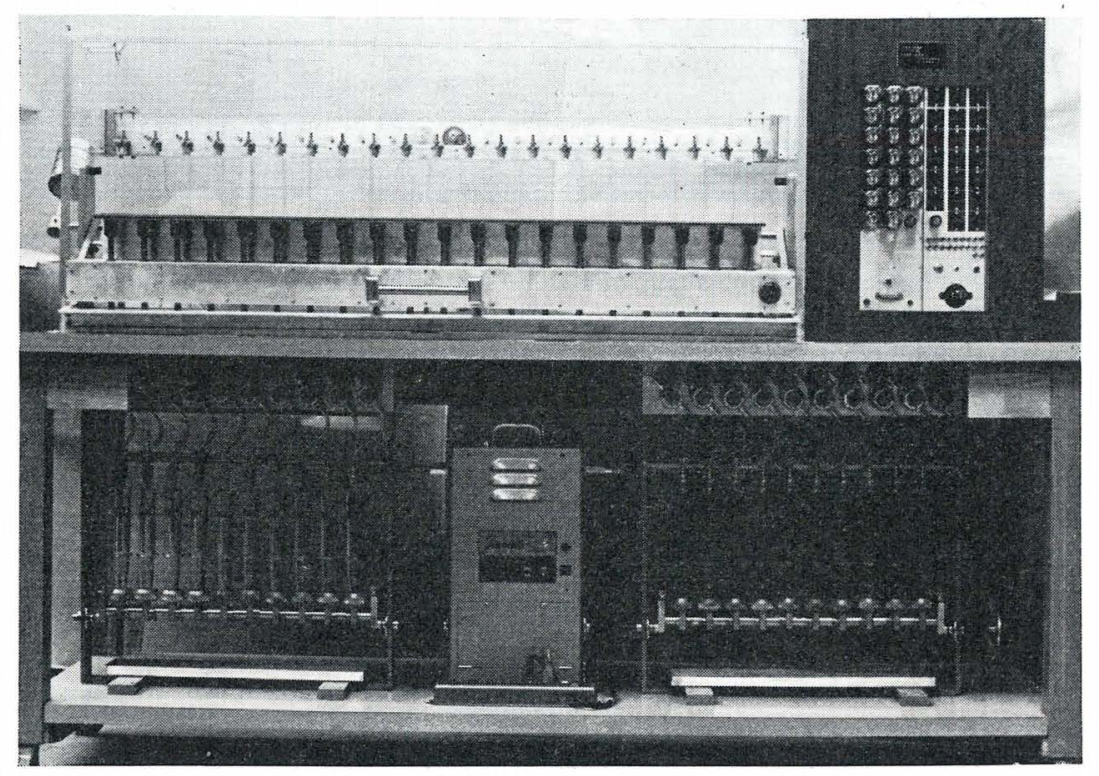

The solenoid valves are activated at the beginning of the syringe downstroke and deactivated at the bottom of the stroke for the 2-second \pm 0.2 puff. As the cigarets burn to the desired butt length and through the thread, the actuator arms on the respective ports are released and deactivate the microswitches which in turn deactivate the low voltage relays. The relays stay in a deactivated condition and de-energize the three-way solenoid valves. The solenoid valves are vented to the air and thus prevent the cigarets from being puffed on the next syringe downstroke. When all of the cigarets have reached the designated butt length, the operator then puts the electronic power supply unit into "reset" position which places all components in a "hold" state and sets the unit for the next smoking operation.

The counter sequence of operation begins with the lighting puff when all electronic components in the system are in the "hold" position until the first puff is taken. The counter unit is energized with the lighting puff and all counters receive ten pulses from the signal generator and record the total of ten. Each puff adds ten to the counter totals. As the char line of the cigarets burns through the thread, the microswitches are deactivated. Burn-through may occur while the cigaret is statically burning or during the 2-second puff. With the deactivation of the microswitches the relays and solenoid valves deactivate, venting the solenoid valves to the air. Also, the counters which are coupled electronically to the main power supply, are stopped. After five cigarets have been smoked on each port, the total is read from the counters and divided by the number of cigarets smoked to determine the average "puffs per cigaret".

2o-Port Electric Cigaret Lighter

An electric cigaret lighter was designed and fabricated in an aluminum channel, $3.5 \mathrm{in} . \times 3.5$ in. $\times 52$ in., so that it can be attached to the smoking cabinet at both ends by arms that are secured and made to pivot in bushings. The arms are counter-weighted to facilitate raising and lowering the lighter to its igniting position. 


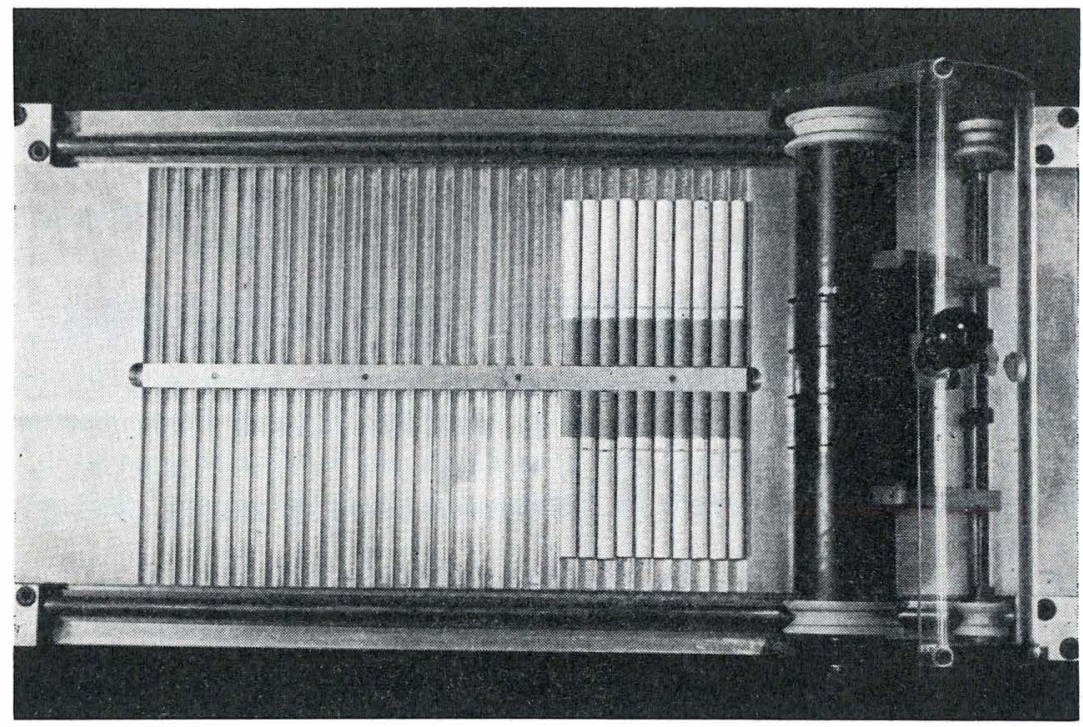

Spaced evenly along the 52-inch length of the channel are 20 manually adjustable lighters. The lighters are 75 -watt, $3 / 4$-inch circular screw base heater elements. The heaters are screwed into sockets attached to sliding hollow shafts which pass through the front and back of the aluminum channel. Wires from the heater sockets are led through the hollow shafts, out through a slot in the middle of the shaft and into the channel interior. The wires are coupled to two BUSS bars which are connected to 110-volt A.C. current.

The operator raises the lighter and quickly slides each individual heater to contact the cigarets and then turns the lighter on about 30 seconds prior to the machine puff. After lighting the cigarets, the lighter is lowered to its resting base, the 20 heater shafts are pushed forward and a protective heater cover drops over the heaters to protect them and the operator.

\section{Cigaret Butt Length Marking Device}

A cigaret butt length marking device was fabricated which consists of a plate grooved to accommodate 64 cigarets (see Figure 4). Thirty-two cigarets are placed on each side of the plate with the filter end touching a bar that separates the two areas. The marking assembly passes over the cigarets on nylon rollers and, as it moves, the marking wheels roll over an inked pad and in turn leave marks on the cigarets. The adjustable marking wheels are spaced to leave a mark $5 \mathrm{~mm}$ and $30 \mathrm{~mm}$, respectively, from the butt end of the cigarets on each side of the center separating bar. This device readily marks one cigaret as well as 64 cigarets.

\section{SUMMARY}

An automated smoking machine, and improved associated equipment, has been described. The automatic portion consists of a "string cut-off" technique which instantly and accurately stops the puffing action on cigarets. This is achieved by an electronic sequence that deactivates three-way solenoid valves and vents the smoking train to the air at the syringe. Solenoid deactivation is achieved through the use of microswitches and relays.

An automatic puff-counting unit records the number of puffs taken on the cigarets on each port. The counters are pulsed by a signal generator set for 5 pulses per second. The generator is activated by a 2-second cam and microswitch attached to the 4-second cam that cycles the smoking machine.

Constant puff volume and puff duration are maintained by use of individual syringe eccentric cams that allow precise volume adjustment on each port and solenoid valves that serve as intake and exhaust valves and provide positive action. The solenoid valves are activated by the 2-second cam and microswitch that is synchronized with the puffing downstroke of the syringe. 
The 2.0 \pm o.2-second puff is precisely obtained through the machine's variable speed controlled gear driven electric motor. This feature yields a stable volume and duration regardless of the resistance of the cigarets.

The level of precision obtained previously on the O'Keeffe and Lieser machine was reduced by onethird by the automation developments described in this paper.

ZUSAMMENFASSUNG

Es wird eine automatische Rauchmaschine für das gleichzeitige Abrauchen von 20 Cigaretten beschrieben. Die Maschine unterbricht automatisch den Zug an der brennenden Cigarette, wenn die gewünschte Stummellänge erreicht ist. Dieses wird auf folgende Weise erreicht. Ein Faden, der über der Stummelmarke gespannt ist, brennt durch, wenn die Glutzone die Stummelmarke erreicht. Dadurch wird ein Mikroschalter betätigt, der über Relais ein 3-Wege-Magnetventil in der Weise umschaltet, daß die Vakuumleitung von der brennenden Cigarette getrennt und mit der Außenluft verbunden wird.

Ein automatischer Zugzähler registriert die Zugzahl für jede abgerauchte Cigarette.

Ein konstantes Zugvolumen und eine konstante Zugdauer von 2 sec werden dadurch erreicht, daß jede der 20 Cigaretten durch eine eigene Kolbenpumpe gezogen wird. Das Zugvolumen kann variiert werden.

RÉSUMÉ

On décrit une machine à fumer automatique du type seringue à volume constant qui a les qualités requises pour stopper électroniquement la combustion de cigarettes à longueur voulue du mégot et pour enregistrer le nombre de bouffées. Le système utilise une technique de coupure de «ficelle» qui enclanche un système électronique lorsque la zone de combustion atteint un fil et le brûle. Le système électronique ouvre une prise d'air, quand le fil a brûlé, et empêche ainsi que d'autres bouffées continuent à être tirées de la cigarette. Simultanément, un générateur de signaux, à 5 impulsions par seconde (1o par bouffée de 2 secondes) est interrompu, et les compteurs respectifs cessent leurs enregistrements. La machine à fumer décrite est aussi équipée d'un allumeur électrique à 20 orifices qui possède des positions d'incandescence réglables suivant la longueur des cigarettes.

REFERENCES

1. O'Keeffe, A. E., and Lieser, R. C.: Tob. Sci. 2 (1958) 73.

Acknowledgment

The authors gratefully acknowledge the suggestions and assistance given them by Mr. T. S. Elliott, Mr. G. A. Filias and the Engineering Group.

Authors' address:

Philip Morris Inc., Research Center, P. O. Box 3 D, Richmond, Va., 23206, USA 